\title{
Editorial
}

\section{News and Views from the Editor}

Firstly I would like to wish all our readers, authors and referees a very Happy New Year. My hope for 1993 is that Diabetologia will continue to serve as an effective vehicle for up-to-date and first class information on all aspects of diabetes research. My previous Editorial [1], published on the doorstep of 1992, was entitled "Towards New Horizons" because of the implementation this year of a number of changes to our journal with respect to both the circulation, volume and content. The most exciting of these was the introduction of mandatory subscription for the members of our Association. The extent to which the EASD membership would disagree with such an arrangement was unpredictable, and we were somewhat concerned that major disagreement could, indeed, lead to a decrease in the membership. However, I am pleased that our apprehension was considerably exaggerated and that the number of registered (and thereby subscribing) members of the EASD is now greater than ever (about 3700) which has led to an almost three-fold increase in the circulation of Diabetologia. Our authors should be aware that their printed papers are now circulated in at least 5500 issues of the journal, the majority of which are private copies sent directly to individual members. We hope that the members will discover the benefits of a personal subscription to our journal and appreciate having immediate access to up-to-date coverage of worldwide progress in diabetology.

Not only has the circulation increased, but also the volume of the journal has increased from about 700 pages a year, when we took over in 1989 , to the present 1200 pages. Since the increase in the inflow of manuscripts, from 437 in 1988 to 507 in 1991, has been somewhat less marked than the growth in volume, the acceptance rate has gone from a record low of $24 \%$ in 1990 to about $37 \%$ in 1992. We, like the authors, feel more comfortable with the latter figure, which much better reflects the proportion of good and acceptable manuscripts we receive. It should be underlined, though, that we intend to maintain the highest possible scientific standard, which will probably imply an acceptance rate of less than $40 \%$ in the future.

One factor of critical importance for the success of a scientific journal is its publication time. Our Editorial Of- fice staff (Sarah Hills, Gina Eriksson and Sharon Ford) make every effort to reduce this to a minimum by chasing occasional tardy referees and urging the authors to revise their manuscripts within the four weeks stipulated. The handling of manuscripts in the office seldom exceeds a week although even an Editor sometimes has to leave the pile of manuscripts for a rare holiday or a meeting in a remote country. With an average delay of 7 months between receipt of a manuscript and publication in the journal we feel that our publication time is among the shortest for comparable journals in diabetology. Inevitable delays, however, include the time for postal handling and the printing process. Therefore, as from this year we are offering the possibility for manuscripts to be submitted on diskette, which we hope will shorten the time required to edit and print the journal. For detailed information on the technical aspects of this procedure we refer our authors to instructions published in this and forthcoming issues of Diabetologia.

Although a speedy publication is important, the scientific quality of the published papers remains the most significant for the reputation of a scientific journal. The novelty, conceptual advance and reliability of each paper are therefore qualities which are always taken into account when a manuscript is considered for publication. Whereas the referee reports and, hopefully, the Editor's common sense provide a basis for a reasonably accurate assessment of the first two factors, it is sometimes more difficult to form an opinion on the reliability of the data which are presented. Misconduct, in one form or another, stands out as a particularly serious problem for all those involved in scientific publishing and, unfortunately, one which is extremely difficult to control. Even if it is probably a rare event, I would urge our referees to be aware of this problem and convey any suspicions in a confidential letter to the Editor. Another issue is that of the conflict of interest which occurs when an author has, for instance, the direct financial advantage of having certain data published in a scientific journal. This is something that as a journal we must be aware of, and be prepared to consider guidelines for in the future. 
As you may have noticed, a News Section specifically directed to the members of EASD, is now located at the back of each issue. The material for this section is usually solicited by the Honorary Secretary, presently Professor Alberto Di Lieva, Barcelona, but any contribution of interest to our members is welcome and will be scrutinized and edited by the Honorary Secretary and the Editor-inChief. Information from our President, from the EASD Secretariat in Düsseldorf and from the Study Groups will regularly appear in this section. I would also like to draw your attention to the "For Debate" section for which presumtive authors are invited to submit their personal views and opinions on controversial issues in diabetology. Please note that critique and comments to individual papers in Diabetologia should still be submitted in the form of a Letter-to-the Editor.

The Diabetologia editorial team in Uppsala is now entering its fifth and final year. It has been a great experience to run the journal and we look forward to the coming year with undaunted enthusiasm. The journal will then take a long stride to the warmer latitudes of Northern Italy, where Professor Eleuterio Ferrannini in Pisa will take up the editorship. As from 1 October 1993, all new submissions will be handled by him and his editorial team. Luck- ily for him there are still another nine months to go before he is exiled into the ivory tower of an Editor-in-Chief. I wish him and his associates good luck in their preparations for this task and assure him that, to the best of our ability, we will help to make the transition as smooth as possible.

Finally, I would like to express, on behalf of all those involved in the production of Diabetologia, our deep gratitude to Pierre Lefebvre, Rudiger Landgraf and John Ward who now retire from the Executive Committee of the EASD and whose constant support and active help was instrumental in the implementation of the aforementioned changes to Diabetologia. We include our thanks to the team of Viktor Jörgens, Karen Page and Regina Hecht at the EASD Secretariat in Düsseldorf for their continuous invaluable help.

Claes Hellerström

Uppsala 1 January 1993

\section{References}

1. Hellerström C (1992) Towards new horizons. Diabetologia 35: 1 (Editorial) 